\title{
Moral Exemplars in Education: A Liberal Account
}

\author{
Michel Croce \\ University of Edinburgh \& University of Lisbon
}

\begin{abstract}
This paper takes issue with the exemplarist strategy of fostering virtue development with the specific goal of improving its applicability in the context of education. I argue that, for what matters educationally, we have good reasons to endorse a liberal account of moral exemplarity. Specifically, I challenge two key assumptions of Linda Zagzebski's Exemplarist Moral Theory (2017), namely that moral exemplars are exceptionally virtuous agents and that imitating their behavior is the main strategy for acquiring the virtues. I will introduce and discuss the notions of enkratic exemplars and injustice illuminators and show that we have good reasons to consider them moral exemplars although they fail to satisfy (either of) the key assumptions.
\end{abstract}

[penultimate version; please cite the published version]

\section{Introduction}

A recently revived discussion in the philosophy of education-more precisely, in character educationinquires into whether exposure to role models can offer an effective strategy to foster virtue development. According to the exemplarist tradition, which takes inspiration from Linda Zagzebski's Exemplarist Moral Theory (2017), admiring exceptionally virtuous individuals, i.e. moral exemplars, and thereby becoming suitably disposed to emulating their behavior is a leading strategy in acquiring virtues. Yet, unsurprisingly, it is a matter of controversy who, if anyone, counts as a moral exemplar. Those who endorse a more restrictive view have it that only fully virtuous agents (moral saints) can be considered moral exemplars, whereas proponents of a more concessive view maintain that it is enough for one to be a moral exemplar if they be exceptionally virtuous in one specific respect (moral heroes), provided that they do not entertain vicious behavior in other respects.

This paper takes issue with the exemplarist strategy for fostering virtue development with the specific goal of improving its applicability in the context of education. I shall argue that, for what matters educationally, we have good reasons to endorse a liberal account of moral exemplarity, namely one on which moral exemplars need not always be virtuous or imitable. To achieve this goal, in Section 2, I introduce the standard account of moral exemplarity and Zagzebski's proposed model for helping novices become virtuous via exposure to moral exemplars. In Section 3, after clarifying that my liberalizing project falls within the scope and the requirements of character education (\$3.1), I motivate 
a turn to a liberal account of moral exemplarity. First, I show that two paradigmatic categories of moral exemplars on a standard exemplarist approach might not be imitable (\$3.2). Then, I make a case for two non-standard categories of moral exemplars: enkratic exemplars, who lack virtue, and injustice illuminators, who fail to be imitable (\$3.3).

\section{Moral Exemplars and the Exemplarist Dynamic}

The exemplarist moral theory is a non-conceptual, foundational, moral theory, in which all the fundamental concepts are derived from the notion of a moral exemplar. For example, on Zagzebski's view, a 'virtue' is what we admire in moral exemplars, a 'right act' is what an exemplar would do, and a 'good life' is the kind of life an exemplar desires for themselves and others. 'This view is particularly interesting from an educational standpoint because, as Zagzebski states quite clearly at the beginning of her book, she aims at construing a theory that is 'practically useful. By that, I mean both that it gives us directions on what to do and how to live, and it can be used to make us want to do so' (2017: 3).

For the purposes of this project, the two fundamental features of moral exemplarism are its definition of a moral exemplar and the educational strategies it can offer. As regards the former, moral exemplars are defined as most admirable individuals because they are paradigmatically good (20). What we admire in them is: (1) the psychological sources of their behavior, rather than the external causes that might have contributed to their actions; (2) the acquired psychological features that led them to behave as they do; and (3) the motives of concern for others they have more than any motives of self-interest (63-64). On Zagzebski's view, moral exemplars can be distinguished in three categories: moral heroes are highly admirable for one specific trait, but not necessarily admirable for others; moral saints are moved by altruistic concerns to the extent that we expect them to display not only the virtue of charity but all the virtues (96); ${ }^{2}$ finally, sages are admirable for their extraordinary wisdom (95). ${ }^{3}$

As regards the educational strategies proposed by exemplarism, Zagzebski has not offered a full-fledged account of moral education. However, the overall applicability of her theory to the educational domain is granted by what I have elsewhere called the exemplarist dynamic (Croce 2019: 292293). In short, the exemplarist dynamic offers a phenomenological reconstruction of how one can acquire the virtues on an exemplar-based approach, and consists of three stages: natural admiration, conscientious reflection, and emulation. In the first stage, we detect exemplars by relying on the natural operations of our emotion of admiration. Not only does admiration allow us to individuate the exemplars, it also makes us formulate a judgment that they are so and, as is clear in Zagzebski's theory of emotions (2003), provides us with a motivation to change attitudes towards the exemplar and their deeds, and act as they do in similar situations.

\footnotetext{
${ }^{1}$ For a detailed discussion of Zagzebski's theory see, e.g., Croce (2019).

2 Zagzebski's distinction between moral heroes and moral saints closely resembles the traditional distinction offered in Blum (1988).

3 As an example of a moral hero, Zagzebski (2017: \$3) mentions Leopold Socha, whose exceptional courage allowed him to rescue a group of Jewish refugees by hiding them in the sewage canals in Lwów and feeding them for more than a year. As regards moral saints, Zagzebski points our attention towards the life of Jean Vanier, a Swiss philosophy professor who devoted his life to assisting people with severe mental disabilities. Confucius appears to be the ideal candidate for the category of sages.
} 
The second stage comprises conscientious reflection, which is the main tool we have at our disposal to check up on the natural operations of our emotional dispositions and is key to ensuring that admiration has not misguided us into thinking that someone is a moral exemplar when in fact they fall short of virtue or, worse, are impostors. Reflecting on whether the object of our admiration fits our emotion justifies our trust in the operations of our emotional dispositions, thereby making it rational for us to rely on the emotions that survive reflection over time. Given the fallibility of our natural dispositions, conscientious reflection is an ineludible step if we wish to be in a good position to achieve the virtues by imitating exemplars.

The third stage is what Zagzebski calls 'emulation' (2017: \5), which amounts to a particular form of imitation directed towards both an exemplar's acts and their motives for actions. Emulating the exemplar makes us able to adopt their attitude in the situations in which we find ourselves, which can well differ from those of the exemplar. The point of emulation is rather to develop a virtuous habitus, that is, to form a pattern of response to morally relevant situations as an exemplar would do.

The educational implications of Zagzebski's exemplarism have raised several worries aboutamong other things - the extent to which the exemplarist dynamic can be applied to all students (Tanesini 2016) and the limits of her account of moral admiration (Archer 2019; Szutta 2019; Vaccarezza and Niccoli 2019). My main concern is with how we can make the most of exemplarist moral theory for educational purposes. The analysis that follows will focus on what it takes to consider someone a moral exemplar or, to put it slightly differently, how we should complement or revise Zagzebski's account of moral exemplars to ensure that educators can work with them to foster virtue development in novices.

\section{A Liberal Account of Moral Exemplarity}

\subsection{A Methodological Remark}

Before attempting to improve the usefulness of moral exemplars in virtue education, it is necessary to address a methodological concern with the boundaries of the proposed enterprise. To put it boldly, the question is: how much room for maneuver do we have here? Although Zagzebski has provided quite a detailed, three-tiered, account of what she takes to be a moral exemplar, she has not offered a fullfledged account of how her theory could be applied to educational settings. This fact gives us scope for revising what is needed to arrive at a more operational account of moral exemplarity. In this paper, I shall remain faithful to two main assumptions of character education: first, the idea that promoting human flourishing is the main aim of character education and the acquisition of the virtues is a necessary condition of flourishing (Kristjánsson 2015: 14); and second, the idea that resorting to moral exemplars is not only a legitimate strategy within character education to promote the virtues, but also one that —as Zagzebski and others have suggested (Carr 1991; Porter 2016)—is likely to have advantages over other strategies. 
Nonetheless, one might still worry that departing from Zagzebski's original account of moral exemplars betrays her vision of the educational implications of moral exemplarism. Here are two reasons why I do not think that we should worry about this:

First, since our project aims at assessing how exemplars can be used in educational settings to foster virtue development, it might turn out that educational effectiveness trumps orthodoxy regarding (the exemplarist) moral theory. It is to be expected that theoretical frameworks require adjustments whenever we want to apply them to real-life situations: even more so when a rather ideal moral theory has to be implemented in non-ideal settings like ordinary classrooms.

Second, were it to be the case that the liberal account I shall put forth waters down the notion of a moral exemplar to the point that it is no longer clear whether we can still talk about an exemplarist approach to virtue education, this need not have any consequences at the level of the moral theory. Proponents of moral exemplarism could still hold firm to an ideal understanding of moral exemplarity and the exemplarist dynamic for theoretical reasons, while conceding that in non-ideal situations some moral improvement can arise out of an encounter with less-than-exemplary figures. In short, the very fact that there might be reasons for switching to a liberal notion of a moral exemplar from an educational standpoint is not in itself revealing of any flaw in the moral theory.

In light of these considerations, I suggest that we look at the remainder of this paper as an exercise in pushing the exemplarist model to its limit to get a clear idea of how we can maximize its educational effectiveness. The alternative account of a moral exemplar that I propose liberalizes Zagzebski's exemplarist theory in two specific respects. On the one hand, I shall challenge the third step in the exemplarist dynamic and, in particular, the very idea that emulation is the main way for novices to develop the virtues. In contrast, I will argue that some exceptionally admirable individuals whom we either cannot or do not wish to imitate should nonetheless be regarded as moral exemplars. On the other, I shall challenge the exemplars' virtuousness requirement, that is, the idea that moral exemplars are paradigmatically good individuals. In contrast, I will argue that in some circumstances less-than-virtuous agents can well serve the purposes of moral exemplars.

The argument I shall set forth comprises two parts: in the pars destruens (\$3.2), I will show that two traditional categories of moral exemplars, i.e. moral saints and moral heroes, might not be in the market for emulation as Zagzebski thinks they are; then, in the pars construens (\$3.3), I will offer two non-standard cases of moral exemplars, i.e. enkratic exemplars and injustice illuminators, which will prove that there is more to moral exemplars than Zagzebski thinks.

\subsection{Saints, Heroes, and the Problems with Imitability}

Let us first consider moral saints. As we have seen, it is natural to think of them as the paradigmatic case of moral exemplars, given the fact that they are meant to possess all the virtues and therefore are the most admirable individuals from a moral point of view. On closer inspection, though, it is far from clear that saints can perform the role that moral exemplars are supposed to have on an exemplarist perspective. 
For starters, for the exemplarist dynamic to activate, the novice's admiration should elicit a desire to emulate the exemplar, but it is controversial whether this happens when the exemplary figure before us is a moral saint. As Wolf (1982) nicely put it, it might well be the case that moral perfection is not a particularly desirable model of personal wellbeing. A life devoted to altruistic ideals will surely require complete dedication and will hardly leave room and time for things that, despite being stricto sensu morally irrelevant, nonetheless contribute to the fulfillment of one's wellbeing, such as personal interests, ambitions, a sense of humor, and admiration directed towards non-moral objects. Thus, the fact that morality is the overarching goal of a saint's life will 'require either the lack or the denial of the existence of an identifiable, personal self (424). These considerations elicit some reservations about the extent to which moral saints fit the exemplarist model.

Zagzebski considers Wolf's objection against the desirability of a moral saint's life and contends that Wolf's notion of a moral saint might fail to fit the exemplarist model not because moral saints cannot be imitated, but because they are not admirable in the first place (2017: 25). Zagzebski also seems to concede that there might be cases in which we experience a disconnection between admiration and the urge to emulate (2017: \$6), thereby admitting that the most virtuous category of exemplars in her view might fall somewhat short of imitability.

We need not arrive at a verdict on the desirability of moral sainthood here, as there is another problem that puts enough pressure on the suitability of moral saints for an exemplarist approach to education. The worry is that even if we wished to emulate them, we might not be able to do so, in that the level of virtuousness they exemplify is out of reach for most of us, limited and distracted human beings. This problem is even more pressing in education: with novices, it can be expected that the initial drift made possible by the emotion of admiration gives way to a negative emotion, namely discouragement, as soon as they realize how far away they are from the impressive deeds of the admired saints.

The exemplarist might want to defend Zagzebski's classification of moral exemplars by arguing that moral saints set the threshold for moral perfection while it is moral heroes that make the exemplarist dynamic work in everyday situations. This consideration surely has a point, in that the unique combination of exemplary behavior and moral imperfection typical of heroes provides educators with a more manageable category of exemplars. For the very fact that moral heroes excel in one virtue but display moral flaws makes them appear closer to our own imperfections, thereby revealing that acquiring the virtues requires hard work but might not be beyond our reach.

As I have argued elsewhere (Croce and Vaccarezza 2017: 8-9), deploying moral heroes on an exemplarist approach to education comes with two advantages. First, the educator can quickly direct the novices' attention to one virtue by recalling a specific hero who displays that virtue, while resorting to moral saints does not allow for such a convenient virtue-detecting strategy, since it can be hard for novices to identify which virtues make the saint appear so admirable. Second, the educator can make the novices work on the hero's flaws of character (or vices) by having them reflect on either the negative effects of the hero's vicious habits or how the hero's struggles to overcome their weaknesses allowed them to become exemplars. 
All I have said so far about moral heroes supports their suitability for an exemplarist approach to education. However, it looks as though there might well be cases in which we cannot or do not want to emulate heroes, as we have just seen in the case of saints. One evident limitation to the imitability of heroes has to do with the contexts in which most of us are supposed to live and exercise their virtues, which are often different from-i.e. distant from-the contexts typical of heroic deeds. I cannot wait to exercise courage until I am in the situation of having to rescue a child from a burning house as heroic firemen do, since (hopefully) I will never be in such a position of having to make this lifethreatening decision. Nor can I wait to exercise humility until I acknowledge that hundreds of people shall wish to congratulate me for my heroic deeds, as again the chances that this will happen are extremely low, all things considered. Thus, how can emulation be appropriate as a strategy of becoming more virtuous if we will almost never have to do anything like the actions for which we admire heroes?

Zagzebski addresses this worry when she contends that admiration does not make us want to replicate the hero's actions specifically; rather, it makes us want to be 'the kind of person who would be capable of doing' something as virtuous as the hero's acts in whatever circumstances we find ourselves (2017: 20). To put it differently, one further reason why the exemplarist dynamic requires conscientious reflection on the part of the novice - and the educator's support in the early stages of their moral development - is that they need to understand how they can imitate the hero's actions and motives in different contexts.

Supposing this will suffice as a reply to the first consideration, a second worry concerns the possibility that one does not want to emulate moral heroes, as it is too risky. One way or the other, heroism involves taking a virtuous decision when something deeply valuable is at stake, be it someone's life, profound desires, career prospects, or personal relationships. Despite our admiration for how the hero faces these risks, it might look paradoxical—or at least disproportionate— that in order to acquire the virtues, novices are supposed to desire, judge, and behave like people who are already capable of dealing with such risks.

To my knowledge, exemplarists have one interesting and reasonable way to address at once both this worry (i.e. with the desire to emulate heroes) and the previous worry (i.e. with the possibility of emulating saints). A key suggestion is offered in the following remark by Zagzebski:

Moral improvement comes in stages, and if we aim too high at the outset, we may set ourselves up for failure. Direct imitation of the exemplar may come only after a person has reached a certain level of moral development. Before that, we do better at imitating persons who are better than we are, but not so much better that we cannot clearly see the path to becoming like the exemplar (2017: 25).

As should be clear from this passage, Zagzebski seems to contemplate the possibility that, at some early stages of moral development, her own categories of moral exemplars might not facilitate the novice's path toward virtue. ${ }^{4}$ Several commentators (Croce 2019; Croce and Vaccarezza 2017; Han et al. 2017; Szutta 2019) have seriously considered this remark and have suggested that we should broaden the

\footnotetext{
${ }^{4}$ I take this remark to provide further support for the project of liberalizing the traditional account of moral exemplars.
} 
domain of moral exemplars. In particular, Han et al. (2017) have shown that novices are less willing to engage with the virtuous deeds of historic exemplars than they are with attainable and relevant exemplars - that is, with figures who provide the novices with the perception that emulating them is within their reach and who exercise the virtues in situations familiar to the novices.

The pars destruens of my argument has shown that if exemplarism is meant to have a concrete educational import, as Zagzebski claims, then we need to reconsider the boundaries of the domain of moral exemplarity, in that we might have reasons against deploying moral saints and moral heroes in the exemplarist dynamic. In the pars construens, I shall outline two fundamental directions in which those boundaries should be broadened.

\subsection{Enkratic Exemplars and Injustice Illuminators}

The first non-standard case of moral exemplarity I want to propose is represented by what I will call enkratic exemplars. The enkeratês in Aristotle's ethics (NE VII) is someone who acts in accordance with reason but experiences a feeling that is contrary to reason. As such, enkrateia-i.e. continence-is morally worse than virtue in that the latter involves no internal conflict within the agent to act in accordance with reason. It is precisely for this reason-i.e. the fact that the enkratês struggles to do the right thing - that enkratic exemplarity could constitute a decisive step in virtue development on an exemplarist approach, or so I shall argue. Let me offer two cases of enkratic exemplars which could suggest how these figures might be deployed in educational settings.

On the one hand, an educator might present the novices with a tale like the following: To reach his workplace, every morning Dave gets on a train that stops in several touristy areas. He is regularly asked for information by visitors from all countries. Dave is annoyed by their presence and continued requests and feels the desire to ignore them or pretend not to speak any language they would understand. Despite struggling with himself, usually he decides to help the visitors out and address their queries. On the other hand, opportunities for shedding light on enkratic exemplarity might easily arise out of little episodes in the everyday life of a classroom. For example, a student who finds something another classmate has lost and returns it despite feeling the desire to keep it for themselves would amount to a good case of an enkratic exemplar in an ordinary setting.

As should be evident, enkrateia cannot be a mark of moral exemplarity for someone who already knows how to master passions and desires when they conflict with reason. Those who relentlessly and happily help out any person in need around them and those who never have the feeling to keep any found item for themselves will not see anything special—more precisely, admirable—in Dave's and the student's behavior. However, the moral population encompasses other categories of individuals, such as vicious agents, akratic individuals - i.e. those who experience a feeling that is contrary to reason and who often act in accordance with that feeling despite being aware that they are going against reason - and children who are approaching moral considerations about the relationship between passions and reason for the first time. My contention is that for these categories of the moral population, enkratic individuals might constitute a legitimate kind of moral exemplars, if not the most appropriate one. 
What makes them suitable for moral exemplarity from an educational standpoint is the particular combination of admirability, imperfection, and the struggle they display. Their imperfection is evident in the fact that acting well is neither natural nor easy for them, but at the same time, it is also a clue of relevance and attainability, to stick with the terminology of Han et al. (2017). Moreover, their struggle provides the novice with an opportunity to reflect on the interaction between reasons and passions, starting with exemplars whose actions are likely to be much closer to the novice's everyday experience than the typical narratives of moral heroes and saints.

One might worry that this whole idea of enkratic individuals as moral exemplars goes against the exemplarist approach in that the admiration towards them cannot be fitting if we just remind ourselves that they fall short of moral virtue. Let me try to appease this critic with two considerations. First of all, to fulfill the admiration stage in the exemplarist dynamic we need motivating admiration, that is, an emotion that generates the desire to imitate the exemplar and activates positive attitudes and reasoning about their moral virtuousness. As I have tried to argue in \$3.2, it is far from clear that motivating admiration is what we can expect from novices when we present them with moral heroes and moral saints: quite to the contrary, there is a fair chance that admiration for those figures will backfire and actually discourage the novices.

Secondly, there is surely something admirable about the behavior of enkratic individuals: first, they act well; second, they do so out of good motives; third and most importantly, they do so as a result of an inner struggle. This shall suffice to conclude that whenever a child, an akratic agent, or a vicious one admires an enkratic exemplar, their admiration fits its object. A similar verdict has implications for Zagzebski's cognitivist view of emotions. For one thing, it suggests that an emotion's fittingness might depend not only on the feeling and the object towards which the feeling is directed, but also on the agent's perspective - in the case of admiration, on their moral position. This explains why admiration towards enkratic exemplars is fitting for the aforementioned categories of agents, but not for those who are at later stages in moral development. For another, it suggests that an emotion's fittingness might admit of degrees, with enkratic exemplars sitting near the low end of the spectrum and moral saints near the high end.

The proposed liberalization of moral exemplarity also has wider implications for the exemplarist dynamic. As regards the third stage, it goes without saying that the imitability of enkratic exemplars is somewhat limited, as there is nothing in their behavior that those who already master passions should emulate. Yet, emulating enkratic exemplars could constitute a reasonable path for vicious and akratic individuals to abandon their bad habits and move closer to moral virtue. Furthermore, regardless of their imitability, exposure to enkratic exemplars can lead novices, akratics, and vicious agents to increase the awareness of their limitations and start questioning their behavior: no doubt this constitutes an essential building block in the path towards becoming virtuous. This analysis of enkratic individuals made a case for the idea that less-than-virtuous agents can count as moral exemplars and, more generally, that the educational function of moral exemplars goes beyond the standard model of virtue development by emulation.

The second non-standard case of moral exemplarity I shall offer puts further pressure on emulation as the third stage of the exemplarist dynamic and is constituted by what I shall call injustice 
illuminators. Injustice illuminators are people who shed light on relations of oppression in a community, such as 'the invisibilization of certain phenomena, experiences, problems, and even entire subjectivities' (Medina 2013: 192). Typically, injustice illuminators are members of oppressed groups and display what Josè Medina calls meta-lucidity, namely an awareness of the effects of oppression in our social structures and the limitations of dominant ways of seeing within our communities (2013: \$5).

Before accounting for why we should make room for injustice illuminators in our theory of moral exemplarity, I shall clear the ground of a preliminary worry and explain why I have decided not to stick to Medina's original label of 'epistemic heroes' (186) to identify those who excel in metalucidity. I can offer two reasons in favor of this choice, which is more conceptual than terminological in spirit. The first reason is that injustice illuminators need not be epistemic heroes. According to Medina, epistemic heroes are extraordinarily courageous and meta-lucid 'subjects who under conditions of epistemic oppression are able to develop epistemic virtues with a tremendous transformative potential' (186). Rosa Parks is a paradigmatic case of an epistemic hero, namely one who left an unforgettable mark in the history of the civil rights movement by refusing to give up a bus seat to a white man who was requesting her to move, in Alabama in 1955. However, an injustice illuminator can well be a student or a colleague who manages to cast light on some sort of small-scale discrimination that has been perpetrated in the classroom or workplace, yet it is not required that their virtuous intervention has the 'tremendous transformative potential' Medina has in mind when he talks about epistemic heroes. Thus, while epistemic heroes are injustice illuminators by definition, the opposite is not true.

The second reason is that the contribution of injustice illuminators goes well beyond the epistemic domain and therefore considering them as mere epistemic exemplars will not do justice to these individuals. I cannot go further into whether epistemic heroes can count as moral exemplars: my inclination is that they do so, but Medina is clear that the contribution they give pertains to the epistemic domain. All I need to make my point about injustice illuminators is to highlight that their contribution towards calling out instances of epistemic injustice (Fricker 2007) encompasses both an epistemic and an ethical dimension. As Fricker clearly points out (122-ss), the phenomenon of epistemic (in)justice is hybrid in nature, in that it has to do with (a lack of) truth and (in)justice at the same time. Thus, there seems nothing wrong in considering injustice illuminators as moral exemplars insofar as their acts contribute to counteracting unjust dynamics or restoring just practices within a given community.

Having clarified why we should not reduce the notion of an injustice illuminator to that of epistemic heroes, we can now explain why a theory of moral exemplarity should make room for injustice illuminators. As I have done for enkratic exemplars, I shall argue that the behavior of injustice illuminators is both admirable in some respects and conducive to the moral development of the novices who admire them.

The activity of injustice illuminators can be unpacked as follows: first, they have the ability to see what is morally and/or epistemically unjust about a given situation, relationship, or social structure; second, they realize how members of a community might be blind to the problem - that is, by failing to notice the wrong - if not part of the problem themselves - e.g. by being those who perpetrate the wrong; and third, they find a way to reveal such wrong, to make it evident in the relevant community. 
Doing so requires both courage and meta-lucidity, that is, two character traits for which injustice illuminators are worthy of our admiration. However, there is a clear limit to their imitability, in that one cannot simply choose to be part of an oppressed group and therefore one cannot decide to emulate the deeds of those who are sensitive to injustices and discrimination because they have suffered (or are suffering) them.

Thus, one might worry that injustice illuminators cannot be moral exemplars if the emotion of admiration we might experience towards them fails to elicit emulation—at least for those members of a community who do not belong to an oppressed minority. In fact, this should be the verdict issued by a traditional exemplarist approach. A liberal account, though, can accommodate the idea that injustice illuminators are moral exemplars insofar as the encounter with these figures motivates those who admire them to reflect on the problem highlighted, changing their attitudes towards the victims of injustice, and elaborating ways of counteracting the injustice. Although, strictly speaking, only other members of oppressed groups may emulate them, what makes them exemplars is the contribution they make towards fostering human flourishing. They might not allow us to develop the virtues they display as we would expect from models of what I shall call direct exemplarity, but they still allow us to get closer to moral virtue, as models of indirect exemplarity can well do.

An opponent of the liberal account of moral exemplarity might want to object that the proposed distinction between direct and indirect forms of exemplarity just is an ad hoc maneuver to avoid the evident problem that injustice illuminators do not fit the exemplarist dynamic. As a reply to this objection, I shall point out that support for the idea of indirect exemplarity can be found in Archer's (2019) recent account of admiration. As he clearly argues, Zagzebski's emulation view of admiration - i.e. the thesis that admiration is meant to provide motivation for emulating the object of admiration - is problematic: on the one hand, it is committed to the idea that the object of admiration can only be human beings, while there seems to be no principled reason why we could not also admire nonhuman animals and objects; ${ }^{5}$ on the other, it unduly restricts the range of appropriate responses to admiration to a desire to emulate the object of admiration. As a more promising alternative, Archer puts forth and defends the value promotion view of admiration, according to which in prototypical cases of admiration, an agent who experiences admiration will be motivated to promote the value(s) that they admire in the object of their admiration' (146).

Once we acknowledge that 'a desire to emulate is one of several ways in which admiration typically motivates' (148), it becomes evident that indirect exemplars and, in particular, injustice illuminators can be legitimately considered as moral exemplars. As I have argued, admiration for them promotes a range of morally valuable achievements such as raising one's sensitivity to epistemic and moral injustice and eliciting counteracting attitudes to prevent the perpetration of unjust social dynamics. Furthermore, as Sherman (2016) has it, the process of changing attitudes towards the victims of injustice and elaborating ways to counteract it requires developing and deploying other virtues, such as vigilance, humility, and conscientiousness. These considerations motivate the conclusion that injustice illuminators can count as moral exemplars and therefore provide support for a liberal account of moral exemplarity, as injustice illuminators amount to a case of non-imitable moral exemplars.

\footnotetext{
${ }^{5}$ See also Korsgaard (2019) on the distinction between human beings as exemplars and exemplary things.
} 


\section{Conclusion: Advantages of a Liberal Account of Moral Exemplarity}

Let me summarize the main take-home messages of the liberalizing project I have undertaken in the previous section and stress the implications of the proposed arguments for the exemplarist dynamic. After showing in the pars destruens of my argument that moral saints and heroes might not fit the exemplarist dynamic as Zagzebski thought, in the pars construens I signaled two directions in which the standard account of moral exemplarity should be liberalized if we care about its applicability in educational contexts. On the one hand, I showed that moral virtue is not a necessary requirement of moral exemplarity, as enkratic individuals can be moral exemplars for young children as well as akratic and vicious adults. On the other, I showed that imitability is not a necessary feature of moral exemplars, in that injustice illuminators can be considered exemplars despite the fact that most of us will never be in a position to emulate their behavior.

My proposal calls for a liberalization of the exemplarist dynamic, for considering emulation as the only appropriate motivational response to admiration is unduly restrictive. The liberal approach is more promising in that it allows us to be pluralist about the ways in which the encounter with moral exemplars can promote moral value. Whenever emulation is not a realistic opportunity, exposure to moral exemplars may still allow novices to change their attitudes towards some morally relevant circumstances or find ways of counteracting injustice. Both activities are in fact likely to promote virtue development as not only Zagzebski but also proponents of character education expect from an exemplarist approach to moral education.

As a final remark, let me stress that the liberal account I have defended herein has an important virtue, namely the fact that it is not just liberal from a theoretical standpoint, but it is also liberating from an educational perspective. For starters, the idea that emulation should not always be the expected outcome of a novice's interaction with moral exemplars frees novices from the ambiguity of not knowing whether they should become able to replicate the exemplar's deeds. The account further reduces the pressure on novices by showing that a realistic path towards human flourishing might require intermediate steps in which they should be exposed to enkrateia rather than exceptional virtue. Finally, the account is also liberating for educators, who need not necessarily present novices with almost-flawless exemplars and then deal with the side effects of an admiration that backfires, but who can rather resort to more manageable exemplars insofar as they are relevant, attainable, and sometimes even less-than-virtuous characters.

As anticipated in \$3.1, nothing I have argued in this paper commits Zagzebski and proponents of standard moral exemplarism to give up on any of their theoretical cornerstones. That said, I am also convinced that my arguments suffice to motivate the need for a more plausible and effective educational application of the exemplarist moral theory. ${ }^{6}$

\footnotetext{
${ }^{6}$ I am grateful to Johan Dahlbeck and Morten Korsgaard for including my work in this special issue. I would also like to thank the audience at the workshop "Exemplars in Arendt and Spinoza: Insights for Moral Exemplarism and Education" (University of Malmö) for their comments. Work on this article has received funding from the Fundaçao para a Ciência e a Tecnologia (FCT, Portugal) under grant agreement CEECIND/02143/2017.
} 


\section{References}

Archer, A. 2019. “Admiration and Motivation.” Emotion Review 11(2): 140-150.

Blum, L. 1988. "Moral exemplars: Reflections on Schindler, the Trocmés, and Others." Midwest Studies in Philosophy 13: 196-221.

Carr, D. 1991. Educating The Virtues. London: Routledge.

Copp, D. 2016. "Moral Education versus Indoctrination." Theory and Research in Education 14(2): 149-167.

Croce, M. \& Vaccarezza, M. S. 2017. "Educating through Exemplars. Alternative Paths to Virtue." Theory and Research in Education 15(1): 5-19.

Croce, M. 2019. "Exemplarism in Moral Education: Problems with Applicability and Indoctrination." Journal of Moral Education 48(3): 291-302.

Fricker, M. 2007. Epistemic Injustice: Power and The Ethics of Knowing. Oxford: Oxford University Press. Han, H., Kim, J., Jeong, C. \& Cohen, G. 2017. “Attainable and Relevant Moral Exemplars are More Effective than Extraordinary Exemplars in Promoting Voluntary Service Engagement." Frontiers in Psychology 8: 283.

Korsgaard, M. T. 2019. "Exploring The Role of Exemplarity in Education: Two Dimensions of The Teacher's Task." Ethics \& Education 14(3): 271-284.

Kristjánsson, K. 2015. Aristotelian Character Education. London: Routledge.

Medina, J. 2013. The Epistemology of Resistance. Gender and Racial Oppression, Epistemic Injustice, and Resistant Imagination. Oxford. Oxford University Press.

Porter, S. 2016. "A Therapeutic Approach to Intellectual Virtue Formation in the Classroom.” In J. Baehr (ed.), Intellectual Virtues and Education: Essays in Applied Virtue Epistemology, London, Routledge, pp. 221-239.

Sherman, N. 2016. “There's No (Testimonial) Justice: Why Pursuit of A Virtue Is Not The Solution to Epistemic Justice." Social Epistemology 30(3): 229-250.

Szutta, N. 2019. "Exemplarist moral theory-some pros and cons." Journal of Moral Education 48(3): 280-290.

Tanesini, A. 2016. “Teaching Virtues: Changing Attitudes.” Logos \& Episteme 7(4): 503-527.

Vaccarezza, M. S., and Niccoli, A. 2019. “The Dark Side of The Exceptional: On Moral Exemplars, Character Education, and Negative Emotions." Journal of Moral Education 48(3): 332-345.

Wolf, S. 1982. "Moral Saints." The Journal of Philosophy 79(8): 419-439.

Zagzebski, L. 2003. "Emotion and Moral Judgment." Philosophy and Phenomenological Research 66(1): 104-124.

Zagzebski, L. 2017. Exemplarist Moral Theory. New York: Oxford University Press. 